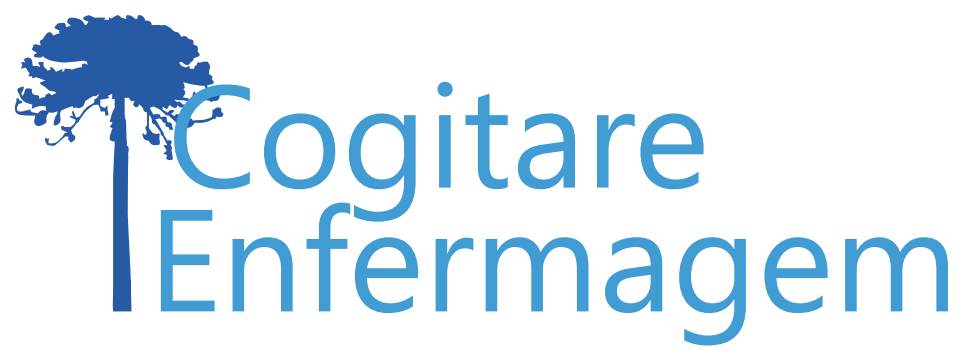

\title{
INSTRUMENTOS DE MENSURAÇÃO RELACIONADOS AO CONHECIMENTO, ADESÃO, ATITUDE E AUTOEFICÁCIA EM DOENÇA FALCIFORME: REVISÃO INTEGRATIVA
}

Sumaya Giarola Cecilio", Valquíria dos Santos Pinto², Sônia Aparecida dos Santos Pereira², Aline de Abreu Silvestre Sales ${ }^{4}$, Clarissa Fernandes Goulart ${ }^{5}$, Lilian Kelen de Aguiar ${ }^{6}$

\section{RESUMO}

Objetivo: identificar, na literatura nacional e internacional, instrumentos de mensuração existentes para medir os domínios conhecimento, autoeficácia, atitude e adesão ao tratamento no contexto da doença falciforme.

Método: revisão integrativa realizada por meio da busca de artigos nos periódicos indexados nas bases de dados: CINAHL, LILACS, PubMed e WOS, de acordo com os critérios de inclusão: artigos originais, que utilizaram instrumentos para medir algum dos domínios pesquisados (conhecimento ou adesão ao tratamento ou autoeficácia ou atitudes da pessoa com doença falciforme, independente da faixa etária da população alvo) dos últimos 15 anos (2003 a 2018).

Resultados: foram incluídos 11 artigos dos 379 levantados, com cinco instrumentos identificados.

Conclusão: Os instrumentos identificados poderão fornecer indicadores relacionados aos domínios psicossociais e comportamentais relacionados à doença falciforme.

DESCRITORES: Anemia Falciforme; Doença Crônica; Inquéritos e Questionários; Autoeficácia; Conhecimento.

COMO REFERENCIAR ESTE ARTIGO:

Cecilio SG, Pinto V dos S, Pereira SA dos S, Sales A de ASS, Goulart CF, Aguiar LK de. Instrumentos de mensuração relacionados ao conhecimento, adesão, atitude e autoeficácia em doença falciforme: revisão integrativa. Cogitare enferm. [Internet]. 2019 [acesso em "colocar data de acesso, dia, mês abreviado e ano"]; 24. Disponível em: http://dx.doi.org/10.5380/ce.v24i0.60897.

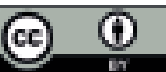

Este obra está licenciado com uma Licença Creative Commons Atribuição 4.0 Internacional.

${ }^{1}$ Enfermeira. Doutoranda em Enfermagem. Universidade Federal de Minas Gerais. Belo Horizonte, MG, Brasil. $\odot$ ${ }^{2}$ Enfermeira. Universidade Federal de Minas Gerais. Belo Horizonte, MG, Brasil.

${ }^{3}$ Pedagoga. Doutora em Enfermagem. Universidade Federal de Minas Gerais. Belo Horizonte, MG, Brasil. $\odot$

${ }^{4}$ Enfermeira. Mestranda em Enfermagem. Universidade Federal de Minas Gerais. Belo Horizonte, MG, Brasil. 9

${ }^{5}$ Discente de Enfermagem. Universidade Federal de Minas Gerais. Belo Horizonte, MG, Brasil. 0

${ }^{6}$ Enfermeira. Doutoranda em Enfermagem. Universidade Federal de Minas Gerais. Belo Horizonte, MG, Brasil. $(2)$ 


\title{
MEASUREMENT INSTRUMENTS REGARDING KNOWLEDGE, ADHERENCE, ATTITUDE AND SELF-EFFICACY IN SICKLE CELL DISEASE: AN INTEGRATIVE REVIEW
}

\begin{abstract}
Objective: To identify in Brazilian and international literature existing measurement instruments to measure the domains of knowledge, self-efficacy, attitude and treatment adherence in the context of sickle cell disease.

Method: This was an integrative review conducted by searching articles in journals indexed in the CINAHL, LILACS, PubMed and WoS databases, according to the following inclusion criteria: original articles that used instruments to measure at least one of the studied domains (knowledge or treatment adherence or self-efficacy or attitudes of people with sickle cell disease, regardless of age of population), in the last 15 years (2003 to 2018).

Results: Of the 379 articles found, 11 were included, and among these, five instruments were identified.

Conclusion: The instruments identified in the literature review can provide indicators relative to the psychosocial and behavioral domains of sickle cell disease.
\end{abstract}

DESCRIPTORS: Sickle Cell Anemia; Chronic Disease; Surveys and Questionnaires; Self Efficacy; Knowledge.

\section{INSTRUMENTOSDEMEDICIÓNRELACIONADOSALCONOCIMIENTO, ADHESION, ACTITUD Y AUTOEFICACIA EN ANEMIA FALCIFORME: REVISIÓN ÍNTEGRATIVA}

\section{RESUMEN:}

Objetivo: Identificar, en la literatura nacional e internacional, instrumentos de medición existentes para medir los dominios conocimiento, autoeficacia, actitud y adhesión al tratamiento en el contexto de la anemia falciforme.

Método: Revisión integrativa realizada a través de la búsqueda de artículos en los periódicos indexados en las bases de datos: CINAHL, LILACS, PubMed y WOS, de acuerdo con los criterios de inclusión: artículos originales que utilizaron instrumentos para medir alguno de los dominios investigados (conocimiento o adhesión al tratamiento o autoeficacia o actitud de la persona con anemia falciforme, independientemente de la faja etaria de la población objetivo) de los últimos 15 años (2003 a 2018).

Resultados: Fueron incluidos 11 artículos de los 379 relevados, habiéndose identificado cinco instrumentos.

Conclusión: Los instrumentos identificados podrán brindar indicadores relacionados a los dominios psicosociales y conductuales relativos a la anemia falciforme.

DESCRIPTORES: Anemia de Células Falciformes; Enfermedad Crónica; Encuestas y Cuestionarios; Autoeficacia; Conocimiento. 
A doença falciforme caracteriza-se por ser uma doença genética e crônica que está associada a alterações das células sanguíneas. Dentre as suas consequências, as mais comuns estão associadas a episódios de dor e danos aos órgãos vitais decorrentes de episódios vaso-oclusivos, principal mecanismo fisiopatológico relacionado às complicações da doença falciforme ${ }^{(1-2)}$.

Invariavelmente, isso demanda da pessoa o seguimento às práticas de autocuidado e diretrizes do tratamento como forma de melhor gerenciar a doença e evitar o seu agravo. Este fato confere a necessidade de acompanhamento das pessoas com essa condição por equipe interdisciplinar nos ambulatórios de especialidades e nas Unidades Básicas de Saúde ${ }^{(3-4)}$.

Entretanto, um dos desafios enfrentados pelos profissionais que acompanham as pessoas com doença falciforme é conseguir promover um comportamento de cuidado com a saúde com consequente adesão ao tratamento. Estimular a adesão é uma das diretrizes das políticas públicas nacionais e internacionais de controle dessa condição e o seu processo deve englobar os aspectos psicossociais que a influenciam, indo além dos enfoques físicos e previsíveis ${ }^{(5-7)}$.

A dimensão psicossocial considera que a realidade e a vivência das pessoas, os seus sentimentos, atitudes, emoções, assim como o conhecimento e as crenças, influenciam o comportamento em saúde. Autores discutem que os fatores psicossociais contribuem, em maior ou menor grau, para comportamentos de adesão ou não adesão ao tratamento de uma condição crônica ${ }^{(8)}$.

Nesse sentido, investigar os domínios psicossociais e comportamentais das pessoas com doença falciforme se apresenta como uma maneira de identificar questões subjetivas do tratamento que precisam ser trabalhadas pelos profissionais da área da saúde como uma forma de promover o cuidado à saúde. Avaliar domínios psicossociais como o conhecimento, crenças de autoeficácia e atitudes, e comportamentais, como a adesão ao tratamento, pode fornecer indicadores sobre os aspectos do tratamento e fornecer subsídios para o desenvolvimento de intervenções educativas, com vistas à promoção ao autocuidado e controle da condição crônica ${ }^{(9-11)}$.

Assim, se faz imprescindível a utilização de instrumentos de mensuração específicos para a investigação desses domínios, porém, que tenham sido elaborados de acordo com referenciais teóricos e metodológicos pertinentes aos objetos pesquisados, com demonstração de propriedades psicométricas satisfatórias. De tal forma, a escolha de um instrumento de mensuração deve ser baseada em critérios pertinentes ao domínio psicossocial ou comportamental trabalhado pelo pesquisador ${ }^{(12-15)}$.

Nesse sentido, esta revisão integrativa buscou identificar, na literatura nacional e internacional, instrumentos de mensuração existentes para medir os domínios relacionados à autoeficácia, adesão ao tratamento, conhecimento e atitude no contexto da doença falciforme, como forma de auxiliar pesquisadores e profissionais da área da saúde na escolha de um instrumento adequado para a investigação de indicadores de cunho psicossocial e comportamental.

\section{MÉTODO}

Foi realizado uma revisão integrativa, de janeiro a maio de 2018. As etapas propostas pelo referencial teórico-metodológico adotado foram: estabelecimento da hipótese ou questão da pesquisa, processo de busca e determinação de critérios e extração das informações, avaliação dos estudos, interpretação dos resultados e apresentação da revisão síntese do conhecimento(16). 
Para guiar a revisão integrativa, formulou-se a seguinte questão: Quais os instrumentos de mensuração têm sido utilizados, nas pesquisas nacionais e internacionais, para medir os domínios relacionados ao conhecimento, adesão ao tratamento, atitude e autoeficácia de pessoas com doença falciforme?

As bases de dados consultadas foram: LILACS (Literatura Latino Americana e do Caribe em Ciências da Saúde), CINAHL (Current Index to Nursing and Allied Health Literature), PubMed (National Center for Biotechnology Information) e Web of Science. Os descritores controlados foram extraídos do Medical Subject Headings (MeSH) e Descritores em Saúde (DeCS), nas línguas portuguesa, inglesa e espanhola: Inquéritos e Questionários, Anemia Falciforme, Doença Falciforme, Doença da Hemoglobina SC, Doença SS, beta-Talassemia, Autoeficácia, Atitude, Atitude para a Şaúde, Adesão e Conhecimento. Para a estratégia de busca utilizou-se a associação entre os operadores booleanos OR e AND.

Foram excluídos os estudos publicados no formato de dissertações, teses, livros e artigos que não descreviam as características do instrumento utilizado ou a sua fonte original. As publicações em duplicidade foram consideradas apenas uma vez. Utilizou-se como critérios de inclusão: artigos originais, que utilizaram instrumentos para medir algum dos domínios pesquisados (conhecimento ou adesão ao tratamento ou autoeficácia ou atitudes da pessoa com doença falciforme, independente da faixa etária da população alvo) dos últimos 15 anos (2003 a 2018).

Para a triagem inicial das publicações, foi realizada a leitura dos títulos e resumos. Os artigos retidos para inclusão na fase preliminar foram revisados independentemente por dois autores, por duas vezes. Em sequência, procedeu-se à segunda análise com leitura na íntegra dos artigos e avaliou-se a pertinência com a proposta do estudo. Os artigos selecionados foram importados para uma biblioteca do Endnote Web e tiveram seus dados registrados em planilha desenvolvida pelas pesquisadoras conforme é recomendado pela literatura (Figura 1).

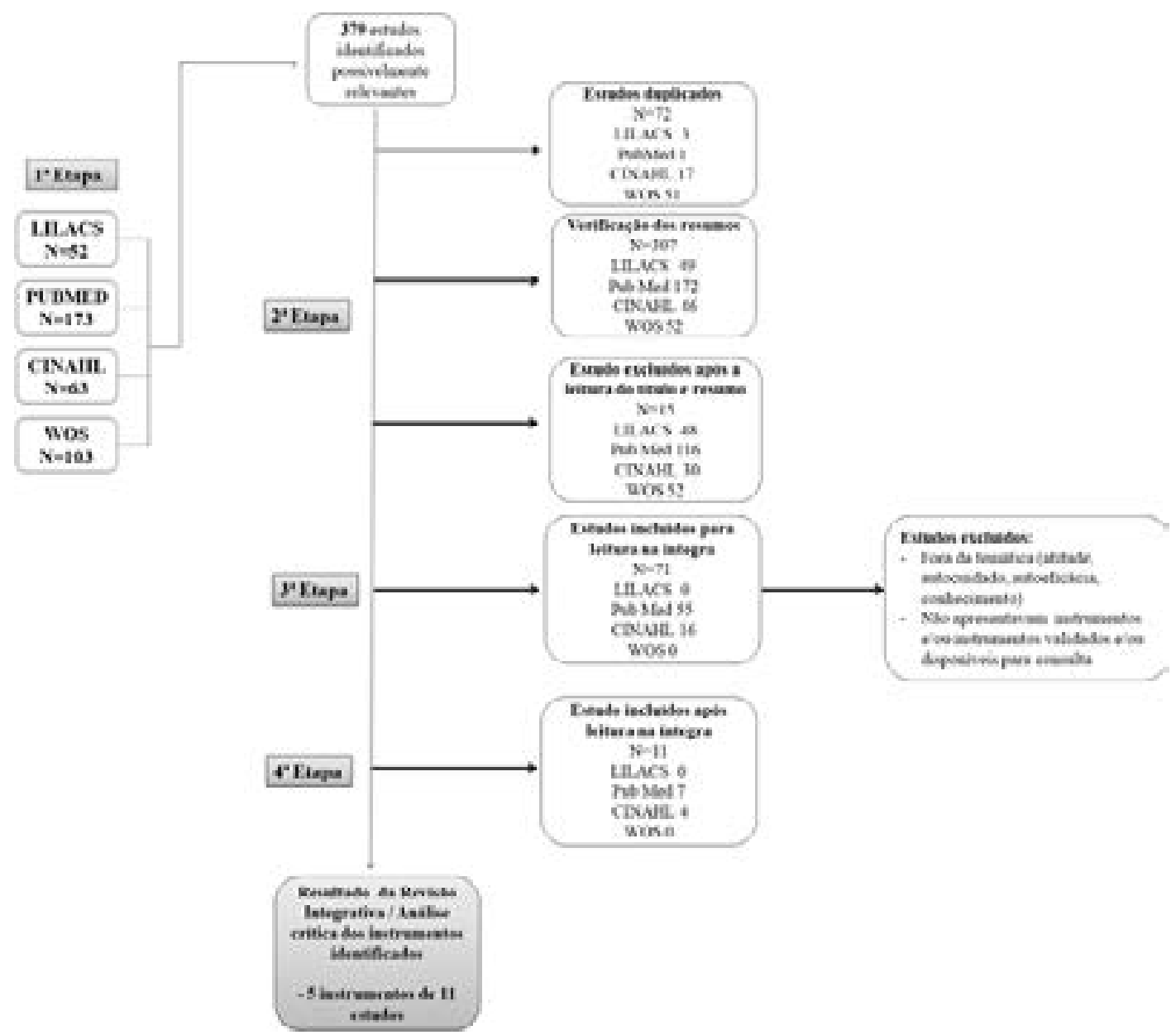

Figura 1 - Método da revisão integrativa sobre instrumentos validados e relacionados aos aspectos psicossociais da doença falciforme. Belo Horizonte, MG, Brasil, 2019 
A avaliação das propriedades de medição e os domínios de cada instrumento foi realizada pela autora principal, que buscou identificar características que tornassem tais escalas/questionários viáveis de uso. A confiabilidade dos instrumentos de mensuração identificados foi pesquisada por meio do valor do Alfa de Cronbach. Cumpre mencionar que apenas instrumentos validados foram considerados como resultados pertinentes da presente revisão.

Utilizaram-se as categorias da Agency for Healthcare Research and Quality (AHRQ) como critérios de classificação de evidências distribuídas em seis níveis: Nível 1: evidências resultantes da meta-análise de múltiplos estudos clínicos controlados e randomizados; Nível 2: evidências obtidas em estudos individuais com delineamento experimental; Nível 3: evidências de estudos quase-experimentais; Nível 4: evidências de estudos descritivos (não-experimentais) ou com abordagem qualitativa; Nível 5: evidências provenientes de relatos de caso ou de experiência; Nível 6: evidências baseadas em opiniões de especialistas.

As recomendações STROBE (Strengthening the Reporting of Observacional Studies in Epidemiology Statement) foram utilizadas como indicador de qualidade metodológica dos artigos com métodos observacional, transversal, caso-controle e de coorte. A avaliação foi dividida em três categorias e realizada por dois avaliadores independentes: $A$ - nos casos dos estudos preencherem valor igual ou maior que $80 \%$ dos critérios; $\mathrm{B}$ - nos casos de cumprimento entre 80 e $50 \%$ dos critérios estabelecidos e C - se houve cumprimento inferior a $50 \%$ dos critérios estabelecidos pelo STROBE ${ }^{(17)}$.

Para a apresentação dos artigos selecionados, elaborou-se um quadro sinóptico, contendo o nome do instrumento utilizado, ano, autor, objetivos e valor do Alfa de Cronbach. As características gerais tais como, domínios e número de itens, foram apresentadas de maneira descritiva.

\section{RESULTADOS}

A partir da busca realizada, foi possível identificar 11 artigos que tinham como escopo mensurar algumas das variáveis: atitude, autoeficácia, adesão e/ou conhecimento de pessoas com doença falciforme e, para isso, recorreram a instrumentos de mensuração disponíveis na literatura e validados por outros autores. Independente do objetivo dos estudos encontrados, esta revisão destinou-se a identificar as propriedades dos instrumentos de medida utilizados por eles e a descrever as suas características. Cumpre-se mencionar que os instrumentos de medida considerados nesta revisão eram destinados, de maneira exclusiva, ao contexto da doença falciforme.

Em alguns estudos (grupo A1, A2, A3; grupo A4 e A5 e grupo A6, A7, A8 e A9) um mesmo instrumento foi utilizado e, por isso, o número de instrumentos encontrados não é semelhante ao número total de estudos analisados. Os estudos A4 e A11 destinaramse à construção de um instrumento e apresentaram em seus resultados o valor dos testes psicométricos realizados. As características das publicações estão descritas no Quadro 1. As características dos instrumentos identificados, bem como a descrição de cada domínio estudado, são apresentadas no Quadro 2. 
Quadro 1 - Características das publicações incluídas na revisão. Belo Horizonte, MG, Brasil, 2019 (continua)

\begin{tabular}{|c|c|c|c|c|c|}
\hline $\begin{array}{l}\text { Artigo (A) - } \\
\text { Título }\end{array}$ & $\begin{array}{l}\text { Nível } \\
\text { de evidência }\end{array}$ & STROBE & Objetivo do estudo & $\begin{array}{l}\text { Instrumento } \\
\text { utilizado no } \\
\text { estudo (i) }\end{array}$ & $\begin{array}{l}\text { Autor do } \\
\text { instrumento/ } \\
\text { ano }\end{array}$ \\
\hline $\begin{array}{l}\text { A1. Correlates } \\
\text { of Pain-rating } \\
\text { Concordance } \\
\text { for Adolescents } \\
\text { With Sickle Cell } \\
\text { Disease and Their } \\
\text { Caregivers }^{(18)}\end{array}$ & $\begin{array}{l}\text { Estudo } \\
\text { descritivo } \\
\text { Nível IV }\end{array}$ & A & $\begin{array}{l}\text { Examinar as relações entre } \\
\text { dor e conhecimento de } \\
\text { adolescentes com doença } \\
\text { falciforme. }\end{array}$ & \multirow{3}{*}{$\begin{array}{l}\text { i1. Children's } \\
\text { Hospital of } \\
\text { Philadelphia } \\
\text { (CHOP) } \\
\text { Transition } \\
\text { Knowledge } \\
\text { Questionnaire } \\
\text { for SCD (TKQ) }\end{array}$} & \multirow{3}{*}{$\begin{array}{l}\text { Newland JA } \\
\text { et al (2008) } \\
\text { (20) }\end{array}$} \\
\hline $\begin{array}{l}\text { A2. A family- } \\
\text { based } \\
\text { randomized } \\
\text { controlled trial of } \\
\text { pain intervention } \\
\text { for adolescents } \\
\text { with sickle cell } \\
\text { disease }{ }^{(19)}\end{array}$ & $\begin{array}{l}\text { Estudo } \\
\text { quase- } \\
\text { experimental } \\
\text { Nível III }\end{array}$ & $A$ & $\begin{array}{l}\text { O estudo teve dois objetivos: } \\
\text { determinar a eficácia de } \\
\text { uma intervenção cognitivo- } \\
\text { comportamental para } \\
\text { adolescentes com doença } \\
\text { falciforme e investigar as } \\
\text { variáveis psicossociais: } \\
\text { conhecimento da doença, } \\
\text { autoeficácia e comunicação } \\
\text { familiar. }\end{array}$ & & \\
\hline $\begin{array}{l}\text { A3. Factors } \\
\text { Influencing } \\
\text { Independence } \\
\text { in Adolescents } \\
\text { With Sickle Cell } \\
\text { Disease }^{(20)}\end{array}$ & $\begin{array}{l}\text { Estudo } \\
\text { descritivo } \\
\text { Nível IV }\end{array}$ & $A$ & $\begin{array}{l}\text { Investigar as relações } \\
\text { existentes entre: conhecimento } \\
\text { sobre a doença falciforme, } \\
\text { gravidade da doença e o } \\
\text { nível de independência de } \\
\text { adolescentes com doença } \\
\text { falciforme. }\end{array}$ & & \\
\hline $\begin{array}{l}\text { A4. Development } \\
\text { of a Screening } \\
\text { Instrument of } \\
\text { Adherence in } \\
\text { Pediatric Sickle } \\
\text { Cell Disease }\end{array}$ & $\begin{array}{l}\text { Estudo } \\
\text { descritivo } \\
\text { Nível IV }\end{array}$ & $A$ & $\begin{array}{l}\text { Avaliar as propriedades } \\
\text { psicométricas do Self Care } \\
\text { Inventory - Sickle Cell (SCl-SC). }\end{array}$ & \multirow{2}{*}{$\begin{array}{l}\text { i2. Self Care } \\
\text { Inventory- } \\
\text { Sickle Cell } \\
\text { (SCl-SC) }\end{array}$} & \multirow{2}{*}{$\begin{array}{l}\text { Hilker KA et } \\
\text { al }(2006)^{(12)}\end{array}$} \\
\hline $\begin{array}{l}\text { A5. Predictors } \\
\text { of Academic } \\
\text { Achievement } \\
\text { for School Age } \\
\text { Children with } \\
\text { Sickle Cell } \\
\text { Disease } \\
\end{array}$ & $\begin{array}{l}\text { Estudo } \\
\text { descritivo } \\
\text { Nível IV }\end{array}$ & $A$ & $\begin{array}{l}\text { Verificar a associação entre } \\
\text { os fatores psicossociais } \\
\text { e comportamentais e o } \\
\text { rendimento escolar de crianças } \\
\text { com doença falciforme. }\end{array}$ & & \\
\hline $\begin{array}{l}\text { A6. An } \\
\text { Examination of } \\
\text { Differences in } \\
\text { Intra-Personal } \\
\text { Resources, } \\
\text { Self-Care } \\
\text { Management, } \\
\text { and Health } \\
\text { Outcomes } \\
\text { in Older and } \\
\text { Younger Adults } \\
\text { with Sickle Cell } \\
\text { Disease }^{(22)}\end{array}$ & $\begin{array}{l}\text { Estudo } \\
\text { descritivo } \\
\text { Nível IV }\end{array}$ & $A$ & $\begin{array}{l}\text { Avaliar a relação entre a } \\
\text { prática de autocuidado e } \\
\text { os resultados de saúde de } \\
\text { jovens e adultos com doença } \\
\text { falciforme. }\end{array}$ & $\begin{array}{l}\text { i3. Sickle Cell } \\
\text { Disease Self- } \\
\text { Efficacy Scale } \\
\text { (SCSS) }\end{array}$ & $\begin{array}{l}\text { Edwards R } \\
\text { et al (2000) } \\
(28)\end{array}$ \\
\hline
\end{tabular}




\begin{tabular}{|c|c|c|c|c|c|}
\hline $\begin{array}{l}\text { A7. Self-efficacy } \\
\text { as a predictor of } \\
\text { adult adjustment } \\
\text { to sickle cell } \\
\text { disease: one-year } \\
\text { outcomes }\end{array}$ & \begin{tabular}{|l|} 
Estudo \\
individual \\
com \\
delineamento \\
experimental \\
Nível II \\
\end{tabular} & $A$ & $\begin{array}{l}\text { Investigar a autoeficácia como } \\
\text { preditor da adaptação adultos } \\
\text { à doença falciforme. }\end{array}$ & \multirow{3}{*}{$\begin{array}{l}\text { i3. Sickle Cell } \\
\text { Disease Self- } \\
\text { Efficacy Scale } \\
\text { (SCSS) }\end{array}$} & \multirow{3}{*}{$\begin{array}{l}\text { Edwards R } \\
\text { et al (2000) } \\
\text { (28) }\end{array}$} \\
\hline $\begin{array}{l}\text { A8. Sleep Quality, } \\
\text { Pain and Self- } \\
\text { Efficacy among } \\
\text { Community- } \\
\text { Dwelling Adults } \\
\text { with Sickle(24) }\end{array}$ & $\begin{array}{l}\text { Estudo } \\
\text { descritivo } \\
\text { Nível IV }\end{array}$ & $A$ & $\begin{array}{l}\text { Examinar as relações entre as } \\
\text { variáveis sociodemográficas, } \\
\text { sono, dor e autoeficácia } \\
\text { de adultos com doença } \\
\text { falciforme. }\end{array}$ & & \\
\hline $\begin{array}{l}\text { A9. The Influence } \\
\text { of Maternal } \\
\text { Behaviors During } \\
\text { Childhood on } \\
\text { Self-Efficacy } \\
\text { in Individuals } \\
\text { With Sickle Cell } \\
\text { Disease(25) }\end{array}$ & $\begin{array}{l}\text { Estudo } \\
\text { descritivo } \\
\text { Nível IV }\end{array}$ & $A$ & $\begin{array}{l}\text { Investigar a relação entre a } \\
\text { superproteção materna na } \\
\text { infância e a autoeficácia na } \\
\text { idade adulta de pessoas com } \\
\text { doença falciforme. }\end{array}$ & & \\
\hline $\begin{array}{l}\text { A10. Educational } \\
\text { Intervention to } \\
\text { Improve the } \\
\text { Health Outcomes } \\
\text { of Children } \\
\text { With Sickle Cell } \\
\text { Disease } \\
\end{array}$ & $\begin{array}{l}\text { Estudo } \\
\text { quase- } \\
\text { experimental } \\
\text { Nível III }\end{array}$ & $A$ & $\begin{array}{l}\text { Avaliar a efetividade de uma } \\
\text { intervenção educativa na } \\
\text { melhora do conhecimento de } \\
\text { cuidadores e crianças com } \\
\text { doença falciforme. }\end{array}$ & $\begin{array}{l}\text { i4. } \\
\text { Questionnaire } \\
\text { to assess } \\
\text { knowledge } \\
\text { of sickle cell } \\
\text { disease (QAK- } \\
\text { SC) }\end{array}$ & $\begin{array}{l}\text { Shahine R et } \\
\text { al }(2014)^{(26)}\end{array}$ \\
\hline $\begin{array}{l}\text { A11. A validated } \\
\text { measure of } \\
\text { adherence } \\
\text { to antibiotic } \\
\text { prophylaxis } \\
\text { in children } \\
\text { with sickle cell } \\
\text { disease }^{(27)}\end{array}$ & $\begin{array}{l}\text { Estudo } \\
\text { descritivo } \\
\text { Nível IV }\end{array}$ & A & $\begin{array}{l}\text { Realizar a construção e a } \\
\text { validação do Sickle Cell } \\
\text { Antibiotic Adherence Level } \\
\text { Evaluation (SCAALE) }\end{array}$ & $\begin{array}{l}\text { i5. Sickle Cell } \\
\text { Antibiotic } \\
\text { Adherence } \\
\text { Level } \\
\text { Evaluation } \\
\text { (SCAALE) }\end{array}$ & $\begin{array}{l}\text { Duncan et al } \\
(2016)^{(27)}\end{array}$ \\
\hline
\end{tabular}

Legenda: A- artigo; i- instrumento.

Quadro 2 - Características dos instrumentos de mensuração validados relacionados aos aspectos psicossociais ou comportamentais da doença falciforme identificados nos estudos. Belo Horizonte, MG, Brasil, 2019 (continua)

\begin{tabular}{|l|l|l|l|l|l|}
\hline Instrumento & $\begin{array}{l}\text { Objetivo do } \\
\text { instrumento }\end{array}$ & $\begin{array}{l}\text { Domínio } \\
\text { pesquisado }\end{array}$ & $\begin{array}{l}\text { Subdomínios } \\
\text { pesquisados }\end{array}$ & $\begin{array}{l}\mathbf{N}^{\circ} \text { de itens } \\
\text { Opções e } \\
\text { Interpretação das } \\
\text { respostas }\end{array}$ & $\mathbf{C I}^{\star}$ \\
\hline $\begin{array}{l}\text { Children's } \\
\text { Hospital of } \\
\text { Philadelphia } \\
\text { (CHOP) }\end{array}$ & $\begin{array}{l}\text { Mensurar o } \\
\text { conhecimento } \\
\text { do paciente } \\
\text { com doença } \\
\text { falciforme } \\
\text { Knowledge } \\
\text { Questionnaire } \\
\text { na fase de } \\
\text { transição de } \\
\text { jovem para } \\
\text { adulto. }\end{array}$ & $\begin{array}{l}\text { Domínio } \\
\text { psicossocial } \\
\text { conhecimento: } \\
\text { o saber sobre a } \\
\text { doença falciforme } \\
\text { e os cuidados e } \\
\text { ações necessárias } \\
\text { para o seu } \\
\text { controle. }\end{array}$ & $\begin{array}{l}\text { a) fisiopatologia; } \\
\text { b) genética; } \\
\text { c) manifestações/ } \\
\text { complicações físicas } \\
\text { d) tratamento; } \\
\text { e) autocuidado; } \\
\text { f) responsabilidades } \\
\text { psicossociais ou de } \\
\text { desenvolvimento; } \\
\text { g) sistema de prestação } \\
\text { de cuidados de saúde. }\end{array}$ & $\begin{array}{l}25 \text { (20) } \\
\text { Múltipla escolha } \\
\text { (certo/errado) } \\
\text { Número de } \\
\text { acertos é } \\
\text { considerado } \\
\text { (> ou } \\
\text { <conhecimento) }\end{array}$ & 0,71 \\
\end{tabular}




\begin{tabular}{|c|c|c|c|c|c|}
\hline $\begin{array}{l}\text { Questionnaire } \\
\text { to assess } \\
\text { knowledge } \\
\text { of sickle cell } \\
\text { disease }\end{array}$ & $\begin{array}{l}\text { Mensurar o } \\
\text { conhecimento } \\
\text { do paciente } \\
\text { adulto com } \\
\text { doença } \\
\text { falciforme. }\end{array}$ & $\begin{array}{l}\text { Domínio } \\
\text { psicossocial } \\
\text { conhecimento: } \\
\text { o saber sobre a } \\
\text { doença falciforme } \\
\text { e os cuidados e } \\
\text { ações necessárias } \\
\text { para o seu } \\
\text { controle. }\end{array}$ & $\begin{array}{l}\text { a) modo de transmissão } \\
\text { da doença; } \\
\text { b) principais } \\
\text { complicações da } \\
\text { doença; } \\
\text { c) papel do baço; } \\
\text { d) intervenções } \\
\text { terapêuticas; } \\
\text { e) manejo de febre e dor } \\
\text { em casa. }{ }^{(26)}\end{array}$ & $\begin{array}{l}25 \\
\text { Dicotômica } \\
\text { (verdadeiro/ } \\
\text { falso) } \\
\text { Número de } \\
\text { acertos é } \\
\text { considerado (> ou } \\
\text { <conhecimento) }\end{array}$ & 0,76 \\
\hline $\begin{array}{l}\text { Self Care } \\
\text { Inventory- } \\
\text { Sickle Cell }\end{array}$ & $\begin{array}{l}\text { Avaliar a } \\
\text { adesão ao } \\
\text { autocuidado } \\
\text { do paciente } \\
\text { pediátrico } \\
\text { com doença } \\
\text { falciforme. }\end{array}$ & $\begin{array}{l}\text { Domínio } \\
\text { comportamental } \\
\text { adesão: medida } \\
\text { de relato dos } \\
\text { pais sobre os } \\
\text { comportamentos } \\
\text { de adesão ao } \\
\text { tratamento/ } \\
\text { autocuidado das } \\
\text { crianças com } \\
\text { doença falciforme. }\end{array}$ & $\begin{array}{l}\text { a) comportamento geral } \\
\text { em saúde (ingestão de } \\
\text { água, medicamento e } \\
\text { dieta); } \\
\text { b) gestão da doença } \\
\text { falciforme (atividades de } \\
\text { autocuidado); } \\
\text { c) manejo da dor; } \\
\text { d) padrão do sono. (12) }\end{array}$ & $\begin{array}{l}19 \\
\text { Escalonada (tipo } \\
\text { Likert) } \\
\text { Escores mais altos } \\
\text { indicam melhor } \\
\text { adesão. Os pais } \\
\text { podem indicar se } \\
\text { algum item não é } \\
\text { aplicável ao filho. }\end{array}$ & 0,88 \\
\hline $\begin{array}{l}\text { Sickle Cell } \\
\text { Antibiotic } \\
\text { Adherence } \\
\text { Level } \\
\text { Evaluation }\end{array}$ & $\begin{array}{l}\text { Avaliar a } \\
\text { adesão ao } \\
\text { medicamento } \\
\text { (antibiótico } \\
\text { profilático) } \\
\text { do paciente } \\
\text { pediátrico } \\
\text { com doença } \\
\text { falciforme. }\end{array}$ & $\begin{array}{l}\text { Domínio } \\
\text { comportamental } \\
\text { adesão: medida } \\
\text { de relato dos } \\
\text { pais sobre os } \\
\text { comportamentos } \\
\text { de adesão ao } \\
\text { tratamento } \\
\text { medicamentoso } \\
\text { das crianças com } \\
\text { doença falciforme. }\end{array}$ & $\begin{array}{l}\text { a) horário da medicação; } \\
\text { b) dosagem da } \\
\text { medicação; } \\
\text { c)farmacocinética da } \\
\text { medicação; } \\
\text { d) plano de cuidados } \\
\text { relacionado à } \\
\text { medicação; } \\
\text { e) lembrete para uso da } \\
\text { medicação; } \\
\text { f) comunicação entre } \\
\text { paciente e profissional; } \\
\text { g) contexto de uso da } \\
\text { medicação. (27) }\end{array}$ & $\begin{array}{l}28 \\
\text { Escalonada (tipo } \\
\text { Likert) } \\
\text { A resposta } \\
\text { "Sempre" reflete } \\
\text { melhor adesão } \\
\text { para algumas } \\
\text { questões e a } \\
\text { pior adesão para } \\
\text { outras questões. } \\
\text { O questionário } \\
\text { faz referência } \\
\text { aos últimos três } \\
\text { meses da rotina } \\
\text { medicamentosa } \\
\text { do entrevistado. }\end{array}$ & 0,89 \\
\hline $\begin{array}{l}\text { Sickle Cell } \\
\text { Disease Self- } \\
\text { Efficacy Scale }\end{array}$ & $\begin{array}{l}\text { Avaliar a } \\
\text { autoeficácia } \\
\text { do paciente } \\
\text { jovem e } \\
\text { adulto com } \\
\text { doença } \\
\text { falciforme. }\end{array}$ & $\begin{array}{l}\text { Domínio } \\
\text { psicossocial } \\
\text { autoeficácia: } \\
\text { crença que a } \\
\text { pessoa tem } \\
\text { sobre as suas } \\
\text { capacidades } \\
\text { pessoais de } \\
\text { enfrentar e superar } \\
\text { os desafios } \\
\text { relacionados ao } \\
\text { autocuidado da } \\
\text { doença falciforme. }\end{array}$ & NA & $\begin{array}{l}9 \\
\text { Escalonada (tipo } \\
\text { Likert) } \\
\text { Pontuações } \\
\text { maiores indicam } \\
\text { uma maior crença } \\
\text { de autoeficácia }{ }^{(28)}\end{array}$ & 0,89 \\
\hline
\end{tabular}

${ }^{*} \mathrm{Cl}$ : consistência interna calculada pelo Alfa de Cronbach (a)

Limitações: Em geral, os autores dos cinco instrumentos destacam limitações de cunho metodológico no que diz respeito às características da amostra da população alvo envolvida na fase dos pré-testes. Todos relacionam este fato a pouca heterogeneidade das amostras, bem como por pertencerem a regiões geográficas específicas, não permitindo, assim, uma adaptação "transcultural" dos instrumentos. 
Os estudos identificados nesta revisão que avaliaram o domínio psicossocial autoeficácia ${ }^{(22-25)}$ de pessoas com doença falciforme utilizaram a avaliação específica por meio do Sickle Cell Disease Self-Efficacy Scale ${ }^{(28)}$. Embora existam poucas pesquisas sobre este tema, as apresentadas demonstraram correlações positivas entre a autoeficácia e bons resultados no gerenciamento da condição, como a diminuição de intercorrências clínicas (crises de dor, internações e transfusões sanguíneas) e psicológicas, uma vez que os indivíduos estudados acreditavam na sua capacidade em seguir as ações de cuidado e conseguiam gerir melhor as emoções. Invariavelmente, foi possível perceber que, quanto maior a crença de autoeficácia das pessoas estudadas, maior era a adesão ao tratamento da doença falciforme ${ }^{(22-25)}$.

A adesão ao tratamento de uma condição crônica está relacionada à subjetividade daqueles que a possuem e deve considerar, obrigatoriamente, a dinâmica social, cultural e emocional das pessoas. Além disso, o senso de autonomia e corresponsabilização entre profissionais e a pessoa com doença falciforme são eixos do tratamento, para que a adesão não se constitua um fator impositivo e impessoal(29).

Os estudos que realizaram a mensuração deste domínio comportamental utilizaram os instrumentos Sickle Cell Antibiotic Adherence Level Evaluation e Self Care InventorySickle Cell, os quais fazem referência às diretrizes de cuidado em doença falciforme ${ }^{(12,26-27)}$ e representam importante contribuição para o gerenciamento clínico, programas de pesquisa e iniciativas de intervenção em saúde. A adesão ao tratamento, nos estudos pesquisados, foi focada no público pediátrico e considerou, principalmente, a questão medicamentosa e de manejo da dor.

No tocante ao domínio psicossocial conhecimento(18-20), os estudos que se destinaram a avaliá-lo utilizaram os instrumentos Children's Hospital of Philadelphia Transition Knowledge Questionnaire for SCD e o Questionnaire to assess knowledge of sickle cell disease. As discussões desses dois estudos abordaram que a maioria das pessoas com doença falciforme e seus cuidadores têm um grau inadequado de conhecimento sobre a doença e a sua gestão. Autores trouxeram que a variável psicossocial conhecimento pode ser pesquisada tanto após uma intervenção educativa, para se avaliar a efetividade da intervenção, quanto previamente, como forma de se obter um panorama sobre o que precisa ser trabalhado. Nesse sentido, um método utilizado pelos estudos identificados nesta revisão, para aumentar o conhecimento de jovens, adultos e cuidadores de crianças com doença falciforme, foi a elaboração de materiais educativos de cunho informativo e educativo, com orientações claras e culturalmente sensíveis à população alvo(18-20).

Nesta revisão, não foram identificados artigos que utilizaram instrumentos validados para mensurar o domínio psicossocial atitude, indicando uma lacuna a ser preenchida. A literatura mostra que pessoas com atitude positiva perante a vida e a condição crônica tendem a adotar comportamentos de enfrentamento que contribuem para o cuidado com a saúde ${ }^{(8,30)}$.

Isto posto, é possível sumarizar que a adesão ao autocuidado refere-se ao processo em que a pessoa com doença falciforme desempenha comportamentos para a melhora da saúde e bem-estar, o que irá demandar atitudes compatíveis ao que é preconizado pelas linhas de cuidado em doença falciforme, associado a esforços para minimizar as complicações relacionadas à doença. Nesse contexto, o conhecimento exerce importante influência, uma vez que contribui para a adesão ao autocuidado, bem como para melhor adaptação à doença(9). No que tange à autoeficácia, esta variável psicossocial atua como um preditor do comportamento, em um cenário onde quanto maior a autoeficácia, maior a adesão às práticas de autocuidado e melhores as atitudes perante as adversidades impostas pela doença ${ }^{(10)}$.

No que corresponde à construção dos instrumentos identificados nesta revisão, estas se basearam em teorias pertinentes ao domínio psicossocial e comportamental 
estudado e se apoiaram em três pilares metodológicos recomendados no campo da Psicometria: i) procedimentos teóricos, ii) procedimentos empíricos (experimentais, como testes na população alvo, entrevistas e consultas aos profissionais da área da Saúde) e iii) procedimentos analíticos (estatísticos). A literatura recomenda que na análise estatística de avaliação das propriedades psicométricas, os instrumentos possuam valores referentes à validade e à confiabilidade, geralmente, representados pelos testes: Coeficiente de Correlação Linear, Coeficiente de Correlação Intra-classe e Alpha de Cronbach (a) ${ }^{(31-32)}$.

Contudo, neste estudo, o critério predominantemente adotado pelos autores dos instrumentos analisados foi verificar a confiabilidade calculada pela consistência interna (homogeneidade/Alfa de Cronbach), que apresenta a capacidade do instrumento em reproduzir um resultado de forma consistente no tempo e no espaço ou com observadores diferentes. $\mathrm{O}$ alfa de Cronbach, como medida de consistência interna, estima a confiabilidade dos itens de um questionário. Valores mais altos do alfa de Cronbach indicam maior consistência interna( ${ }^{(31-32)}$.

No contexto brasileiro, mesmo diante da alta incidência da doença falciforme ${ }^{(1-2)}$, não foram identificados instrumentos validados pertinentes aos domínios pesquisados, o que aponta uma lacuna na literatura. Todavia, a construção de um instrumento se constitui uma tarefa complexa e onerosa. De tal forma, a opção pela tradução de um instrumento se justifica por ser uma opção de maior viabilidade econômica, de tempo e recursos humanos,

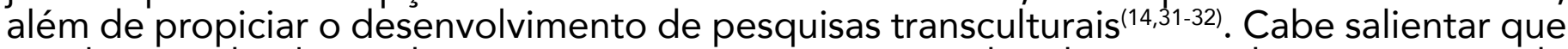
a utilização de algum dos instrumentos aqui apresentados deve considerar as etapas de tradução e adaptação cultural, caso sejam escolhidos pelos pesquisadores brasileiros.

Como limitação desta revisão se cita o fato de alguns estudos que poderiam trazer alguma contribuição terem sido excluídos por não estarem disponíveis na íntegra, ainda que tentativas de contato com os autores originais tenham sido realizadas.

\section{CONCLUSÃO}

Mensurar os domínios psicossociais e comportamentais relacionados aos aspectos do cuidado deve ser tarefa constituinte do acompanhamento de pessoas com doença falciforme. A utilização de instrumentos de mensuração específicos e validados auxilia na investigação e compreensão desses aspectos, constituindo-se, assim, uma importante ferramenta de trabalho dos profissionais da área da saúde envolvidos no contexto da doença falciforme.

Para os quatro domínios pesquisados nesta revisão (autoeficácia, atitude, conhecimento e adesão ao tratamento), foram encontrados cinco instrumentos validados. O domínio mais comumente mensurado foi a autoeficácia, medida pelo instrumento Sickle Cell Disease Self- Efficacy Scale. Não foram encontrados instrumentos relacionados à atitude, embora a literatura atribua importância na sua avaliação.

Acredita-se que esta revisão tenha contribuído para a apresentação de instrumentos destinados a gerar indicadores psicossociais e comportamentais na atenção à doença falciforme e espera-se que esta funcione como uma fonte de consulta para pesquisadores e profissionais da área da saúde.

\section{REFERÊNCIAS}

1. American Society of Hematology. State of Sickle Cell Disease: 2016 Report. Washington: American Society of Hematology. [Internet]. 2016 [acesso em 05 maio 2018]. Disponível em: http://www. scdcoalition.org/pdfs/ASH\%20State\%20of\%20Sickle\%20Cell\%20Disease\%202016\%20Report.pdf. 
2. Serjeant GR.The Natural History of Sickle Cell Disease. Cold Spring Harb Perspect Med [Internet]. 2013 [acesso em 5 maio 2018]; 3(10). Disponível em: https://doi.org/10.1101/cshperspect.a011783.

3. Kanter J, Jordan LB. Improving the Healthcare Model for Management of Adults with Sickle Cell Disease in the PPACA Era. J Hematol Transfus. [Internet]. 2015 [acesso em 5 maio 2018]; 3(1). Disponível em: https://www.jscimedcentral.com/Hematology/hematology-3-1037.pdf.

4. Matthie N, Jenerette C, McMillan S. The Role of Self-Care in Sickle Cell Disease. Pain Manag Nurs. [Internet]. 2015 [acesso em 5 maio 2018]; 16(3). Disponível em: https://www.ncbi.nlm.nih.gov/ pubmed/25439112.

5. Ministério da Saúde (BR). Doença Falciforme: condutas básicas para tratamento. [Internet] Brasília (DF): Ministério da Saúde; 2013 [acesso em 5 maio 2018]. Disponível em: http://bvsms.saude.gov.br/bvs/ publicacoes/doenca falciforme condutas basicas tratamento.144pdf\&gt.

6. Ministério da Saúde (BR). Síntese de evidências para políticas de saúde: melhorando o cuidado de adolescentes com doença falciforme. [Internet]. Brasília (DF): Ministério da Saúde; 2016 [acesso em 5 maio 2018]. Disponível em: http://brasil.evipnet.org/wp-content/uploads/2016/12/SinteseDFalciforme. pdf.

7. Matthie N, Hamilton J, Wells D, Jenerette C. Perceptions of young adults with sickle cell disease concerning their disease experience. J Adv Nurs. [Internet]. 2016 [acesso em 5 maio 2018]; 72(6). Disponivel em: https://doi.org/10.1111/jan.12760.

8. Pereira TTSO, Barros MNS, Augusto MCNA. Health care: biopsychosocial paradigm and subjectivity into focus. Mental. [Internet]. 2011 [acesso em 5 maio 2018]; 9(17). Disponível em: http://pepsic.bvsalud. org/scielo.php?script=sci abstract\&pid=S1679-44272011000200002\&lng=pt\&nrm=iso\&tlng=en.

9. Ahmadi M, Shariati A, Jhani S, Tabesh H, Keikhaei B. The Effectiveness of Self-Management Programs on Self-Efficacy in Patients With Sickle Cell Disease. Jundishapur J Chronic Dis Care. [Internet]. 2014 [acesso em 5 maio 2018]; 3(3). Disponivel em: https://www.researchgate.net/publication/290918962 The Effectiveness of Self-Management Programs on Self-Efficacy in Patients With Sickle Cell Disease.

10. Adewoyin AS, Alagbe AE, Adedokun BO, Idubor NT. Knowledge, attitude and control practices of sickle cell disease among youth corps members in benin city, Nigeria. Ann lbd Pg Med. [Internet]. 2015 [acesso em 5 maio 2018]; 13(2). Disponível em: https://www.ncbi.nlm.nih.gov/pmc/articles/PMC4853875/.

11. Adegbola M. Spirituality, Self-Efficacy, and Quality of Life among Adults withSickle Cell Disease. South Online J Nurs Res. [Internet]. 2011 [acesso em 5 maio 2018]; 11(1). Disponível em: https://www.ncbi.nlm. nih.gov/pmc/articles/PMC3137798/.

12. Hilker KA, Jordan SS, Jensen S, Elkin TD, lyer R. Development of a screening instrument of adherence in pediatric sickle cell disease. J Child Health Care. [Internet]. 2006 [acesso em 5 maio 2018]; 35.

Disponível em: https://doi.org/10.1207/s15326888chc3503 3.

13. Bhatt K, Reid ME, Lewis NA, Asnani MR. Knowledge and Health Beliefs of Jamaican Adolescents With Sickle Cell Disease. Pediatr Blood Cancer. [Internet]. 2011 [acesso em 5 maio 2018]; 57. Disponível em: https://doi.org/10.1002/pbc.23091.

14. Coluci MZ, Alexandre NM, Milani D. Construction of measurement instruments in the area of health. Cienc. saude colet. [Internet]. 2015 [acesso em 5 maio 2018]; 20. Disponível em: http://dx.doi. org/10.1590/1413-81232015203.04332013.

15. Curcio R, Lima MHM, Alexandre NMC. Diabetes mellitus related tools adapted and validated to Brazilian culture. Rev. Eletr. Enf [Internet]. 2011 [acesso em 5 maio 2018]; 13(2). Disponível em: http:// dx.doi.org/10.5216/ree.v13i2.9476.

16. Whittemore R. Combining evidence in nursing research: methods and implications. Nurs Res. [Internet]. 2005 [acesso em 5 maio 2018]; 54(1). Disponível em: https://www.ncbi.nlm.nih.gov/ pubmed/15695940. 
17. Von Elm E, Altman DG, Egger M, Pocock SJ, Gøtzsche PC, Vandenbroucke JP, et al. The Strengthening the Reporting of Observational Studies in Epidemiology (STROBE) statement: guidelines for reporting observational studies. J Clin Epidemiol. [Internet]. 2008 [acesso em 5 maio 2018]; 61(4). Disponível em: https://www.ncbi.nlm.nih.gov/pubmed/17947786.

18. Barakat LP, Simon K, Schwartz LA, Radcliffe J. Correlates of Pain-rating Concordance for Adolescents With Sickle Cell Disease and Their Caregivers. Clin J Pain. [Internet]. 2008 [acesso em 5 maio 2018]; 24. Disponível em: https://doi.org/10.1097/AJP.0b013e3181646038.

19. Barakat LP, Schwartz LA, Salamon KS, Radcliffe J. A Family-Based Randomized Controlled Trial of Pain Intervention for Adolescents with Sickle Cell Disease. J Pediatr Hematol Oncol. [Internet]. 2010 [acesso em 5 maio 2018]; 32(7). Disponível em: https://doi.org/10.1097/MPH.0b013e3181e793f9.

20. Newland JA. Factors Influencing Independence in Adolescents With Sickle Cell Disease. J Child Adolesc Psychiatr Nurs. [Internet]. 2008 [acesso em 5 maio 2018]; 21(3). Disponível em: https://doi. org/10.1111/j.1744-6171.2008.00149.x.

21. Smith KE, Patterson CA, Szabo MM, Tarazi RA, Barakat LP. Predictors of Academic Achievement for School Age Children with Sickle Cell Disease. Adv Sch Ment Health Promot. [Internet]. 2013 [acesso em 5 maio 2018]; 6(1). Disponível em: https://www.ncbi.nlm.nih.gov/pubmed/23459502.

22. Jenerette CM, Phillips RCS. An Examination of Differences in Intra-Personal Resources, Self-Care Management, and Health Outcomes in Older and Younger Adults with Sickle Cell Disease. J Theory Constr Test. [Internet]. 2006 [acesso em 5 maio 2018]; 3(7). Disponível em: https://www.ncbi.nlm.nih.gov/ pmc/articles/PMC2762231/.

23. Edwards R, Telfair J, Cecil H, Lenoci J. Self-efficacy as a predictor of adult adjustment to sickle cell disease: one-year outcomes. Adv Psychosom Med. [Internet]. 2001[acesso em 5 maio 2018]; 63(5). Disponível em: https://www.ncbi.nlm.nih.gov/pubmed/11573035.

24. Adegbola M. Sleep Quality, Pain and Self-Efficacy among Community Dwelling Adults with Sickle Cell Disease. J Natl Black Nurses Assoc. [Internet]. 2015 [acesso em 5 maio 2018]; 26(1). Disponível em: https://www.ncbi.nlm.nih.gov/pubmed/26371356.

25. Jenerette CM, Valrie CR. The Influence of Maternal Behaviors During Childhood on Self-Efficacy in Individuals With Sickle Cell Disease. J Fam Nurs. [Internet]. 2010 [acesso em 5 maio 2018]; 16(4). Disponível em: https://doi.org/10.1177/1074840710385000.

26. Shahine R, Badr LK, Karam D, Abboud M. Educational Intervention to Improve the Health Outcomes of Children With Sickle Cell Disease. J Pediatr Health Care. [Internet]. 2014 [acesso em 5 maio 2018]; 29(1). Disponível em: https://doi.org/10.1016/j.pedhc.2014.06.007.

27. Duncan NA, Kronenberger WG, Hampton KC, Bloom EM, Rampersad AG, Roberson CP et al. A validated measure of adherence to antibiotic prophylaxis in children with sickle cell disease. Patient Prefer Adherence. [Internet]. 2016 [acesso em 5 maio 2018]; 10. Disponível em: https://doi.org/10.2147/PPA. S103874.

28. Edwards R, Telfair J, Cecil H, Lenoci J. Reliability and validity of a self-efficacy instrument specifc to sickle cell disease. Behav Res Ther. [Internet]. 2000 [acesso em 5 maio 2018]; 38. Disponível em: https:// www.ncbi.nlm.nih.gov/pubmed/10957829.

29. Smith M, Aguirre RT. Reproductive attitudes and behaviors in people with sickle cell disease or sickle cell trait: a qualitative interpretive meta-synthesis. Soc Work Health Care. [Internet]. 2012 [acesso em 5 maio 2018]; 51(9). Disponível em: https://doi.org/10.1080/00981389.2012.693580.

30. Betz CL, Lobo ML, Nehring WM, Bui K. Voices not heard: A systematic review of adolescents' and emerging adults' perspectives of health care transition. Nur Outlook. [Internet]. 2013 [acesso em 5 maio 2018]; 61. Disponível em: https://doi.org/10.1016/j.outlook.2013.01.008.

31. Cano SJ, Hobart JC. The problem with health measurement. Patient Prefer Adherence. [Internet]. 2011 [acesso em 5 maio 2018]; 5. Disponível em: https://doi.org/10.2147/PPA.S14399. 
32. Pasquali L. The validity of the psychological tests: is it possible to find the way again? Psic.: Teor. e Pesq. [Internet]. 2007 [acesso em 5 maio 2018]; 23(n.spe). Disponível em: http://dx.doi.org/10.1590/ S0102-37722007000500019.

Recebido: 08/08/2018

Finalizado: 29/04/2019

Autor Correspondente:

Sumaya Giarola Cecilio

Universidade Federal de Minas Gerais

Av. Professor Alfredo Balena, 190, Belo Horizonte, MG, Brasil.

E-mail: sumayacecilio@gmail.com

\section{Contribuição dos autores:}

Contribuições substanciais para a concepção ou desenho do estudo; ou a aquisição, análise ou interpretação de dados do estudo - SGC, VSP

Elaboração e revisão crítica do conteúdo intelectual do estudo - SGC

Aprovação da versão final do estudo a ser publicado - SGC, VSP, SASP, AASS, CFG, LKA

Responsável por todos os aspectos do estudo, assegurando as questões de precisão ou integridade de qualquer parte do estudo - SGC 